FACULTY OF ECONOMICS AND APPLIED ECONOMIC SCIENCES

CENTER FOR ECONOMIC STUDIES

ENERGY, TRANSPORT \& ENVIRONMENT

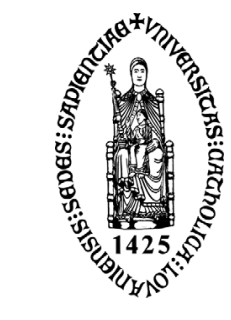

KATHOLIEKE

UNIVERSITEIT

LEUVEN

WORKING PAPER SERIES

$n^{\circ}$ 2001-25

\title{
COST - EFFICIENCY METHODOLOGY FOR THE SELECTION OF NEW CAR EMISSION STANDARDS IN EUROPE
}

\section{Zeger Degraeve (London Business School) Stef Proost (K.U.Leuven-CES-ETE) Gunther Wuyts (K.U.Leuven-CES-ETE)}

November 2001

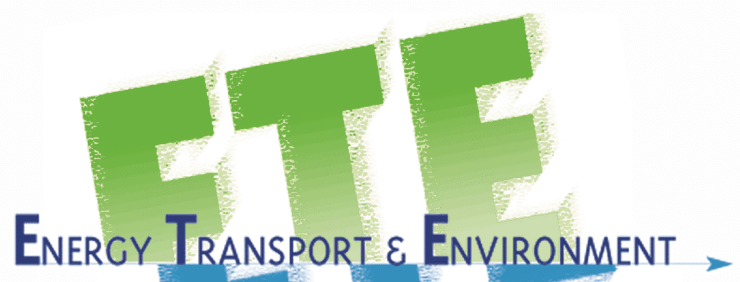

contact:

Isabelle Benoit

KULeuven-CES

Naamsestraat 69, B-3000 Leuven (Belgium)

tel: $\quad+32(0) 1632.66 .33$

fax: $\quad+32(0) 1632.69 .10$

e-mail: Isabelle.Benoit@econ.kuleuven.ac.be

http://www.kuleuven.ac.be/ete 


\title{
COST - EFFICIENCY METHODOLOGY FOR THE SELECTION OF NEW CAR EMISSION STANDARDS IN EUROPE 1
}

\author{
Zeger Degraeve**, STEF PROOST*, Gunther Wuyts* \\ *Faculty of Economics, KULeuven \\ Naamse straat, 69 / 3000 Leuven,Belgium \\ Fax $+32 / 16326796$ \\ Contact: e-mail: stef.proost@econ.kuleuven.ac.be \\ ** London Business School \\ Sussex Place - Regent's Park \\ London NW1 4SA \\ United Kingdom
}

\section{abstract}

In the Auto-Oil Programme, the European Commission looks for emission limits for cars such that the urban air quality targets are reached at minimum cost. This optimisation problem was solved by Degraeve et al. (1998). In this paper we deal with two methodological problems in this cost efficiency approach. We study first what is known as the overachievement problem in cost-effectiveness analysis. In a pure costefficiency approach, there is a tendency to understate the merits of federal regulatory measures: because these measures are uniform they will always do more than required in some regions. We prove this and show how this problem can be solved using minimum information on the benefits of environmental improvements. The second problem we study is the implementation problem of local measures. From a European wide perspective, it may be cost-efficient that some regions take local measures but this is not necessary in the interest of these regions when there is transfrontier pollution. When this behavioural constraint is taken into account, the cost efficient bundle will change. We show how these two considerations affect the selection of optimal emission standards for cars in Europe.

\footnotetext{
1 This paper has been presented at the workshop "Empirical Modeling of the Economy and Environment" June 2001 at ZEW Mannheim. We thank the organizers, participants and in particular Olaf Hölzer for his detailed comments on this paper.
} 


\section{Introduction}

The transport sector has been up to now the most important source of emission for conventional pollutants $(\mathrm{CO}, \mathrm{VOC}, \mathrm{NO} 2, \mathrm{PM})$ in urban areas. It is not only the most important source of emissions in quantity terms but also the most damaging source per unit of emission because of the high concentrations of emissions at low height and the high population density at the places of emissions. It is accepted that 1 ton of emissions emitted at ground level could be 5 to 10 times more damaging than 1 ton emitted at higher height by central heating, industry or power stations. Therefore transport emissions have much more local health effects than the emissions of other sectors.

Achieving an acceptable air quality in urban areas is one of the priorities of the European environmental policy. The EU has up to now relied mainly on emission standards for cars and trucks and on emission standards for other sources to achieve this objective. In this paper we will analyse more in detail the emission by the transport sector.

The first directives of the Commission implementing the catalytic converter standards in 1991 and 1994 (91/441/EEC and 94/12/EC) were criticised heavily by industry. The complaint was that neither the benefits nor the costs of the standards had been assessed. The Auto-Oil Programme (abbreviated as AOP), an assessment exercise of the Commission in collaboration with the automobile industry and the oil industry, has innovated in terms of assessment methodology. In the AOP-I Programme (19921996), an explicit cost-effectiveness approach has been followed. The basic premise was that emission standards on new cars as well as new fuel qualifications are only justified if they are the cheapest way to reach urban air quality targets in EU regions. The complexity of the relation between emission reductions and urban air quality was taken into account via atmospheric air pollution models and there was an effort to make car emission standards compete against other policy instruments as there are fuel qualifications, gasoline taxes etc.. The European Parliament did not follow the recommendations of the AOP-I but opted for more stringent car emission and fuel standards. One of the reasons might have been the unbalanced composition of the AOP-I group where the regulated industry was overrepresented.

The second AOP-II study that started in 1997 takes into account a wider range of policy measures and relies on improved models and data. $\mathrm{CO}_{2}$ emissions are in principle not an issue in the Auto-Oil Programme.

In the Auto-Oil Programme, the European Commission looks for emission limits for cars such that the urban air quality targets are reached at minimum cost. This is a complex exercise because of two difficulties. The first is the presence of economies of scale in car manufacturing. This means that emission limits can not be differentiated regionally and that additional local measures can become interesting to reach the air quality limits. The second difficulty is the presence of transfrontier pollution. Part of the pollution originating in one region ends up damaging other regions in Europe. Selecting emission standards for cars is therefore a complex exercise in which local transport and other measures are traded off against European wide measures on car emission abatement and fuel quality. 
This optimisation problem was solved by Degraeve et al. (1998). They combined information on the cost of different measures and information from air quality models into a cost minimisation framework. It was found that a balanced combination of traditional car emission regulation measures and locally diversified transport measures can achieve the objectives at much lower overall cost. This first exercise has been the basis for the European emission regulations for new cars from 2005 onwards. It was followed by a new more complete cost-effectiveness exercise (called AOP-II).

In this paper we discuss some of the methodological difficulties encountered in this exercise and show how the choice of methodology affects the results.

We study first what is known as the overachievement problem in cost-effectiveness analysis. In a pure cost-efficiency approach, there is a tendency to understate the merits of federal regulatory measures: because these measures are uniform they will always do more than required in some regions. We prove this and show how this problem can be solved using minimum information on the benefits of environmental improvements. In fact this problem is a variant of the problem solved by Oates et al. (1989). The second problem we study is the implementation problem of local measures. From a European wide perspective, it may be cost-efficient that some regions take local measures but this is not necessary in the interest of these regions. This element needs to be integrated in the cost-effectiveness methodology and affects the choice of the optimal bundle. We show how these two considerations affect the selection of optimal emission standards for cars.

Section 2 presents the current AOP-II cost-efficiency methodology. Section 3 discusses the overachievement problem. Section 4 treats the implementation problem of local measures. The last section illustrates both problems numerically. The data, optimisation procedure and effects on the selection of the policy bundle are briefly explained. We conclude with some caveats.

\section{The current cost-effectiveness methodology}

In the Auto-Oil Program of the European Commission, the objective of the analysis is to select emission standards for cars and fuel quality regulations such that in all urban areas, the ambient air quality targets (CO, Benzene, NO2, PM10, Ozone) are met at the lowest cost. Therefore the cost and efficiency of emission standards for cars have to be compared with measures on fuel quality, inspection and maintenance programs, transport demand measures, fiscal measures and emission reduction in non-transport sectors. This is done simultaneously for the period 2000-2020 and for all pollutants considered.

This is a very ambitious goal. The approach followed can best be understood using Figure 1. One can imagine different types of measures to improve the urban air quality. We concentrate first on transport measures. Different categories of measures are illustrated at the bottom of Figure 1. They include vehicle emission standards, fuel quality standards, inspection and maintenance measures, transport demand management and economic instruments (including taxes etc.). 
The potentially effective measures are fed into a transport model (one for each urban area and country considered) in order to determine its overall effect on emissions and its welfare cost. This is necessary because the welfare cost and emission reduction effect of transport demand measures requires working through its effects on all transport markets. As an example consider lower public transport fares. This will increase bus use and bus emissions but will decrease car use and car emissions. The model used for this computation is the TREMOVE transport model (DRI-KULeuven, 1999). The output of this step is a list of measures with, for each area studied, the net emission reduction effect for that area and the gross welfare cost of the emission reduction.

The gross welfare cost of each policy measure consists of three elements: the change in consumer surplus on the transport markets expressed in generalised cost terms ${ }^{2}$, the change in producer surplus plus the change in tax revenue valued at the marginal cost of public funds. A broad welfare concept was needed in order to assess on the same basis the variety of policy measures to be considered. The welfare concept is gross because it does not include the air pollution benefits.

The next step is the selection of the least-cost mix of measures to achieve the target ambient air quality in the different urban areas in Europe. This is done via an optimisation model (LEUVEN II, Degraeve et al.(1998)) that combines information on emission reduction and costs for each potential policy in the transport sector and in other sectors for each emission region with air quality modelling relations that translate emission reductions in each emission region into changes in ambient air quality in all

European urban areas. This problem is solved simultaneously for all selected urban areas, all pollutants and for the whole period 2000-2020.

The mathematical model used in this second step is set out in detail in appendix 1 . Three factors are responsible for the complexity of this model. First, there is the interaction between different policy measures (the total effect of one measure can be smaller than the sum of two measures). Next, there is the large number of combinations of measures that can be used. The different measures are considered as discrete steps so that the model is an integer optimization problem. Finally there is the interaction between the different urban problems due to the transboundary effects of ozone and the uniformity constraint for the global measures.

In the two next sections, we discuss the two methodological problems in the present approach..

\footnotetext{
2 The generalised cost of a trip or a kilometre on a transport market equals the sum of the resource cost, the time cost and the taxes paid. This price concept allows to take into account the behavioural response to changes in congestion levels via changes in the time costs.
} 


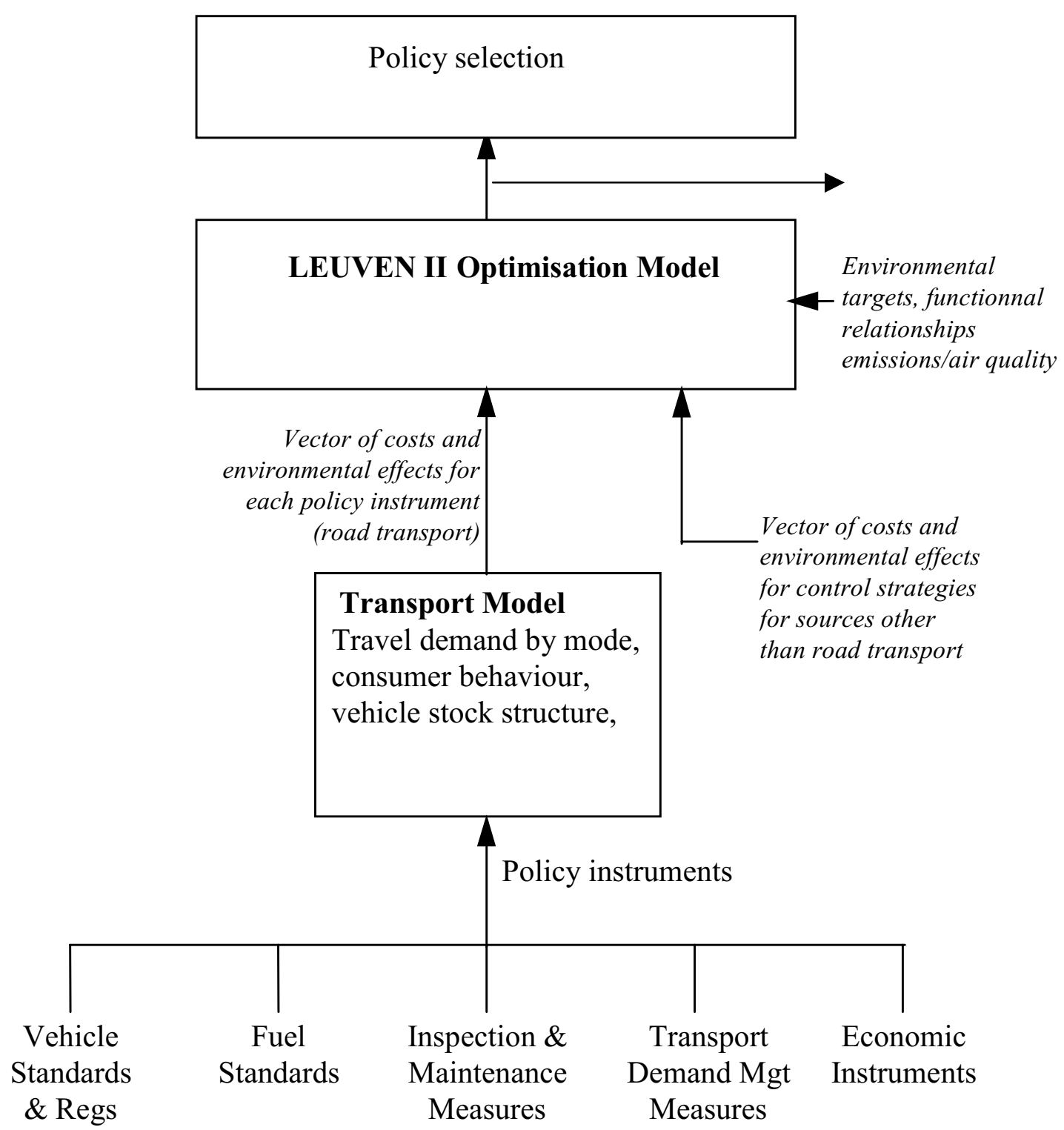

Figure 1 Structure of the Auto-Oil II cost effectiveness analysis

\section{The overachievement problem}

In a cost-effectiveness analysis such as AOP-II, overachievements of targets cannot be neglected. Apart from the benefits of a cleaner environment, neglecting may also lead to solutions that are biased against the use of global (or federal) measures. Emission limits for cars are such a global measure. We will now first develop a simple example to illustrate the type of problem that has to be solved

Consider 2 regions (A and $\mathrm{B}$ ) and 2 types of measures ( $\mathrm{x}$ and $\mathrm{y})$. The intensity at which both types of measures are introduced in region $\mathrm{A}$ is denoted by $\mathrm{x}^{\mathrm{A}}$ and $\mathrm{y}^{\mathrm{A}}$, while $x^{B}$ and $y^{B}$ represent the intensities in region $B$. The cost of introducing measures $\mathrm{x}$ and $\mathrm{y}$ in region $\mathrm{A}$ is given by a cost function $\mathrm{C}^{\mathrm{A}}\left(\mathrm{x}^{\mathrm{A}}, \mathrm{y}^{\mathrm{A}}\right)$. For region $\mathrm{B}$, a similar 
notation is used. Ambient air quality objectives are expressed as reductions in concentration compared to a given baseline and are denoted by $\mathrm{Q}^{\mathrm{A}}$ and $\mathrm{Q}^{\mathrm{B}}$ for regions $\mathrm{A}$ and $\mathrm{B}$ respectively. The diffusion of pollutants is formulated via constant coefficients $t_{A B}$ relating the emissions in $A$ to the reduction in ambient concentration in $\mathrm{B}$.

The cost minimisation problem to be solved is then:

$$
\operatorname{Min}_{x^{A}, x^{B}, y^{A}, y^{B}} C^{A}\left(x^{A}, y^{A}\right)+C^{B}\left(x^{B}, y^{B}\right)
$$

such that

$t_{A A}\left(x^{A}+y^{A}\right)+t_{B A}\left(x^{B}+y^{B}\right) \geq Q^{A}$

$t_{A B}\left(x^{A}+y^{A}\right)+t_{B B}\left(x^{B}+y^{B}\right) \geq Q^{B}$

$x^{A}, x^{B}, y^{A}, y^{B} \geq 0$

The Auto-Oil methodology carefully avoids the use of monetary damage estimates to compute optimal emission reductions. It is well known that air pollution damage estimates can not be determined with precision (for an illustration see the discussion between Krupnick et al.(1991) and Hall et al.(1992) or the ranges in the Extern-E results (Bickel et al.1997). This explains why in policy discussions like Auto-Oil one prefers cost-effectiveness studies that use an absolute ambient air quality target.

In problems with many pollutants and policy instruments that are common to several regions, there will often be overachievement for some pollutants and some regions. Some of the stakeholders in the Auto-Oil debate have pointed to the possible bias against the use of uniform European instruments when overachievement is present. The idea is that European wide emission standards for cars and European wide oil quality standards tend to generate overachievement due to their lack of flexibility. Not attributing any value to this overachievement leads to a bias against uniform measures.

In a pure cost-effectiveness analysis overachievement receives no benefit at all and this is not very logical. Giving a small benefit to overachievement may change the optimal mix of policy measures.

We consider a simplified example to discuss this issue. We assume that there is no transboundary pollution and that cost functions are strictly convex and continuous. There are three types of policy measures: local measures for each of the regions A and $\mathrm{B}$ : $\mathrm{x}^{\mathrm{A}}$ and $\mathrm{x}^{\mathrm{B}}$ and a uniform or global measure $\mathrm{y}$ that affects both regions. By global measure we mean that this measure has to be introduced in both regions at the same intensity. Measures of type y are typically regulatory emission standards for cars or some oil quality standards. The cost-effectiveness problem (1) can then be rewritten as:

$$
\operatorname{Min}_{x^{A}, x^{B}, y} C^{A}\left(x^{A}\right)+C^{B}\left(x^{B}\right)+C(y)
$$

such that

$$
\begin{aligned}
& x^{A}+y \geq Q^{A} \\
& x^{B}+y \geq Q^{B}
\end{aligned}
$$


The first order conditions for this problem are:

$$
\begin{array}{ll}
x^{A} \geq 0 & \frac{\partial C^{A}}{\partial x^{A}}-\lambda^{A} \geq 0 \\
x^{B} \geq 0 & \frac{\partial C^{B}}{\partial x^{B}}-\lambda^{B} \geq 0 \\
y \geq 0 & \frac{\partial C}{\partial y} \quad-\lambda^{A}-\lambda^{B} \geq 0
\end{array}
$$

If at the optimal solution $\bar{x}^{A}, y, \bar{x}^{B}>0$ then there is no overachievement because if there was an overachievement, one could always decrease total costs by reducing the local measure intensity and this contradicts the optimality of $\bar{x}^{A}, y, \bar{x}^{B}>0$. On the other hand, if at the optimal solution $\bar{x}^{A}, y>0, \bar{x}^{B}=0$ then overachievement is possible in $\mathrm{B}$.

We will now show that overachievement and its treatment can have important impacts on the selection of the least cost bundle. This type of problems is present in many cost-effectiveness analyses. Oates et al. (1989) examined the relative efficiency of standards and tradable permits for a cost-effectiveness problem in which certain air quality targets had to be met. They found that standards tend to give rise to more overachievement. When this overachievement is not valued, one will overestimate the advantage of tradable permits. Here we analyse a problem not related to the choice of instruments but the choice of measures that are more or less flexible.

What impact can be expected from valuing overachievement? If we give credits $\mathrm{s}^{\mathrm{A}}$ and $\mathrm{s}^{\mathrm{B}}$ to overachievement of the ambient air quality objectives in region $\mathrm{A}$ and $\mathrm{B}$ and add deduct these credits from the objective function in (2), we obtain new first order conditions for our previous optimisation problem:

$$
\begin{array}{ll}
x^{A} \geq 0 & \frac{\partial C^{A}}{\partial x^{A}}-\lambda^{A}-s^{A} \geq 0 \\
y \geq 0 & \frac{\partial C}{\partial y}-\lambda^{A}-s^{A}-\lambda^{B}-s^{B} \geq 0 \\
x^{B} \geq 0 & \frac{\partial C^{B}}{\partial x^{B}}-\lambda^{B}-s^{B} \geq 0
\end{array}
$$

Assume you start with $\mathrm{s}^{\mathrm{A}}, \mathrm{s}^{\mathrm{B}}=0$ and $\mathrm{x}^{\mathrm{A}}, \mathrm{y}>0$ but $\mathrm{x}^{\mathrm{B}}=0$ and overachievement in region $B$. In this case, increasing the credits for overachievement $s^{A}$ and $s^{B}$ is likely to improve the ranking of measure $y$ and could lead to more overachievement. To see this, check what happens when $\mathrm{s}^{\mathrm{A}}$ or $\mathrm{s}^{\mathrm{B}}$ are increased starting from 0 . With $\mathrm{s}_{\mathrm{A}}$ increasing nothing changes because there was initially no overachievement so as long as $s_{A}$ is smaller than the marginal cost $\lambda^{\mathrm{A}}>0$ of achieving the air quality target in $\mathrm{A}$ there is no interest in increasing $\mathrm{x}^{\mathrm{A}}$. Consider now a small increase in $\mathrm{s}^{\mathrm{B}}$. The optimal use of measure $\mathrm{x}^{\mathrm{B}}$ is not affected as long as the credit for overachievement is smaller than the marginal cost of measure B. But the use of measure $y$ will be increased as: 
$\frac{\partial \mathrm{c}}{\partial \mathrm{y}}-\mathrm{s}_{\mathrm{B}}=\lambda^{\mathrm{A}}=\frac{\partial \mathrm{c}^{\mathrm{A}}}{\partial \mathrm{x}^{\mathrm{A}}}$

so that measure $\mathrm{y}$ has become more interesting to use than measure $\mathrm{x}^{\mathrm{A}}$.

We see that the ranking between global measures and local measures is twisted again more to global measures when credits are given to overachievement. Introducing benefit measures for pollution reduction matters for the selection of instruments.

Of course we could also discuss the problem of underachievement. Reaching the target air quality in some regions like Athens may be impossible in the short term. It is important to foresee this possibility by using a maximum estimate for the cost of underachievement. Combining benefits and fines would bring us closely to the stepwise incentive function advocated by Roberts and Spence (1976) to solve the regulation problem with imperfect knowledge about abatement costs.

The optimization problem that is presented in the appendix allows for over- and underachievement of the air quality targets and takes both possibilities into account when determining the best policy mix for the different regions. In the objective function (8.5.1), the second and the third sum give the total benefit for overachievement. This is the amount by which the targets for the different (local and regional) pollutants are exceeded in the different regions multiplied by the credit that is given to such an averachievement. The amounts are determined in the constraints (8.5.2) and (8.5.3) and are given by sro $_{\mathrm{ij}}$. The sign of these benefits in the objective function is of course negative since a benefit is a negative cost. The fines for underachievement are represented by the the last two sums in the objective function (8.5.1). The interpretation is very similar to the one of the overachievements, except for the signs since an underachievement is treated as an extra cost.

\section{The implementation problem of local measures}

In this section, we will discuss a second problem-type that can be encountered in an analysis such as the Auto-Oil Programme. In the selection of the optimal mix, one compares local and European measures using the same welfare cost concept. However ultimately, the optimal mix of measures has to be implemented and this can give rise to some problems as the local policy maker may have a different objective function than the European decision-maker. The optimization model selects the optimal policy mix from a European-wide point of view, but if the European policy maker cannot enforce the regions to implement this strategy, and more specifically the local measures, it is possible that these regions have an incentive to deviate from this optimal mix. We will again illustrate this problem by means of a simple example and afterwards, we will discuss how it is tackled in the LEUVEN II-model.

Let us return to our model (2) in the previous section. Here, it was assumed that there was no transboundary pollution. If we introduce this type of pollution, we can rewrite the model to obtain the optimal mix of uniform measures $\mathrm{y}$ and local measures $\mathrm{x}$ in the following way: 
$\operatorname{Min}_{x^{A}, x^{B}, y} C^{A}\left(x^{A}\right)+C^{B}\left(x^{B}\right)+C(y)$

such that

$t_{A A}\left(x^{A}+y\right)+t_{B A}\left(x^{B}+y\right) \geq Q^{A}$

$t_{A B}\left(x^{A}+y\right)+t_{B B}\left(x^{B}+y\right) \geq Q^{B}$

$x^{A}, x^{B}, y \geq 0$

The first order conditions of this problem are:

$$
\left\{\begin{array}{l}
\frac{\partial C^{A}}{\partial x^{A}}-\left(\lambda^{A} t_{A A}+\lambda^{B} t_{A B}\right)=0 \\
\frac{\partial C^{B}}{\partial x^{B}}-\left(\lambda^{B} t_{B B}+\lambda^{A} t_{B A}\right)=0 \\
\frac{\partial C(\mathrm{y})}{\partial \mathrm{y}}-\lambda^{A}\left(t_{A A}+t_{B A}\right)-\lambda^{B}\left(t_{A B}+t_{B B}\right)=0
\end{array}\right.
$$

Let $\mathrm{x}^{\mathrm{A}},-\overline{\mathrm{B}}, \overline{\mathrm{y}}$ denote the optimal solution. This type of solution has been used in the Auto-Oil decision process. The problem is that the local measures (x) will be decided upon by local governments that use a different objective function. To see this consider the problem solved by the local government $\mathrm{A}$ : to choose $\mathrm{x}^{\mathrm{A}}$ for given $\bar{y}$ and given ${ }_{\mathrm{x}}^{\bar{B}} \neq \bar{x}^{B}$ and where $\mathrm{BEN}^{\mathrm{A}}$ represents the benefits of emission reduction in region $\mathrm{A}$ :

$$
\operatorname{Min}_{x^{A}} C^{A}\left(x^{A}\right)-B E N^{A}\left(t_{A A}\left(x^{A}+\bar{y}\right)+t_{B A}(\bar{x}+\bar{y}+\bar{y})\right)
$$

The interior optimum of this is given by:

$$
\frac{\partial C^{A}}{\partial x^{A}}-\frac{\partial B E N^{A}}{\partial Q^{A}} t_{A A}=0
$$

We need to compare this with:

$$
\frac{\partial C^{A}}{\partial x^{A}}-\bar{\lambda}^{A} t_{A A}-\bar{\lambda}^{B} t_{A B}=0
$$

when one central government decides on the local measures too.

Assume that the local marginal benefits of emission reduction are constant. We see that the local government will not implement sufficient local measures because it does not have the incentives to do so. The optimal mix selected with this methodology is only optimal in as far as the European policy maker can indeed correct the local government behaviour. If this is not so, it may be better to rely less on local measures and use more central measures. 
In the optimization model (detailed in appendix), we solved the implementation problem in a different way. It proved impossible to fully model the two tier problem of the European government, so we try to mimic the problem by imposing that a certain percentage of the air quality targets has to be reached by global measures because of lack of control on the implementation of local measures. These constraints can be found in constraints (8.5.6) and (8.5.7) in the appendix. The intuition for these extra constraints is that we have argued above that if the implementation problem of local measures exists, it may be optimal to select more global measures.

\section{How important is the choice of cost-efficiency methodology - a numerical evaluation}

\subsection{Scope}

The choice of methodology is numerically illustrated for the Auto-Oil I problem, since there were no sufficient data available from AOP II. In AOP-I, seven European regions (Athens, Köln, Den Haag, London, Lyon, Madrid, and Milano) and four pollutants were incorporated in the analysis, which concerns one representative year (2010). Remark that we have one transboundary pollutant (Ozone) and three local pollutants. The goal of the model is then to determine which measure should be introduced in each region to obtain the required air quality objectives at least cost. In order to provide as much flexibility as possible, the model can choose between a wide variety of measures in the transport sector. Also the non-transport sector (e.g. industry or combustion) has been included, such that the model can freely determine the contribution of each sector.

\subsection{Data}

From the mathematical model in the appendix, the data requirements can be determined. First, data on the cost of introducing a measure in a region is needed. Also, the environmental effectiveness of that measure in a region on a pollutant has to be specified. Furthermore, the model demands the required air quality targets and data on emission concentration relationships. Finally, benefits for overachievement and fines for underachievement have to be quantified.

The costs of introducing sets of measures in a region ${ }^{3}$ are based on a welfare cost concept that not only comprises technical costs such as the costs of fitting pollution abatement equipment to vehicles, but also the costs to consumers of behavioral adjustments induced by policy measures, e.g. reductions in mobility. Hence, these

\footnotetext{
3 The objectives and costs of policy measures in a region are assumed to be representative of the countries in which the region is situated. This means, for example, that the total costs of a fuel measure introduced in the Köln region consists of the per vehicle cost (annual mileage times cost per liter) multiplied by the size of the entire German vehicle fleet. Implicitly, therefore, the analysis covers the following countries: Greece, Germany, The Netherlands, United Kingdom, France, Spain and Italy. Clearly, this procedure assumes a significant degree of averaging within countries. Several consequences arise from this assumption. First, although there is no guarantee that the air quality objectives for a pollutant are reached everywhere in a particular country, it nevertheless seems reasonable to assume that large parts of the country satisfy the standard since, the objectives have been formulated for regions, where, air quality problems are relatively severe. Secondly, to the extent that local measures can only be introduced in those parts of a country where they are really necessary, their "true" costs are likely to be overestimated because they would only have to be introduced in non-attainment areas.
} 
costs can be interpreted as total costs to society. The cost of a bundle (see appendix for a definition of the different concepts) is simply the sum of the costs of all sets of control measures in that bundle.

The effectiveness of a set of control measures is defined in terms of emission reductions. In this paper, we use a specific formula to compute the effectiveness of a bundle, the LEUVEN II-model uses a more general and flexible way, based on a treestructure. We refer to the appendix for more details.

Also air quality targets need to be specified, i.e. the percentage reductions in urban emissions as well as in ozone concentrations that are required to bring down air pollution to acceptable levels. Both in the USA and in the EU the basic approach to air quality problems consists of requiring the attainment of uniform air quality standards. Obviously, the first step is the definition of these standards. In the EU air quality standards are based on World Health Organization guidelines and are set at uniform levels across the EU for concentrations of pollutants at different places during different time intervals. These levels are generally thresholds above which health risks become serious or significant damage to vegetation and agriculture occurs.

Although air quality is expressed in terms of concentrations, policies can only affect emissions and this implies that relations between emissions and concentrations will have to be incorporated in the analysis. With the exception of ozone these relations are linear, e.g. a $1 \%$ reduction in NOx emissions, brings down NOx concentrations by $1 \%$. For ozone, these relations are highly nonlinear, but - over certain ranges - they can be approximated by linear functions which link reductions in regional VOC and NOx emissions in region $i$ to changes in ozone levels in region $\mathrm{j}$. This, in turn, is summarized in two so-called "blame" matrices (one for regional NOx and one for regional VOC) the coefficients of which give the percentage reduction in ozone levels in a particular region due to a $1 \%$ reduction in emissions of the corresponding precursor in another region.

Based on the relations above, expected economic growth as well as measures already scheduled in a variety of sectors, a forecast has been made in the context of the Auto/Oil Programme of "baseline" emissions and air quality levels for the year 2010 in seven representative European regions (European Commission 1996). A comparison of those levels with the air quality standards gives a set of required reductions in emissions.

The approach taken for ozone is, however, different. The ozone reduction objectives represent percentage reductions in forecast ozone AOT90 (Accumulative exposure Over a Threshold) figures. AOT90 is defined as the sum of hourly ozone concentrations exceeding 90 parts per million during the months May, June and July. The AOT90 values are calculated for the year 2010 with the EMEP MSC-W model of the Swedish Environmental Research Institute (Simpson 1991, update 1995). The reduction target imposed for AOT90 in our analysis, results from keeping excess ozone levels below $5 \mathrm{ppb}$. Our ozone target can be interpreted as a required reduction in peak ozone concentrations that occur because of man made emissions from transportation and nontransport sources.

Finally, benefits of overachieving certain targets are considered as well. These benefits are defined as the 'reward' for a certain region of overachieving its targets for a certain pollutant. An example of such benefits can be found in a benefit study by IVM et al. (1997). In our paper, we will illustrate the importance of correctly computing these benefits by varying the level. 
As said before, a wide variety of control measures is included. In the appendix it is explained that these control measures are put together in sets, which contains zero, one or more control measures. These sets are then classified in categories. In table 1, an overview is given of the categories and the sets of control measures that are included in the simulations. A broad range of categories is taken into account, as well in the Transport sector as in the Non-Transport sector (Non Transp). Since the focus of AOP-I was on the transport sector, this sector has been split up further. The first subdivision, Technical Standards is broken down in diesel cars (TED) and gasoline cars (TEG) ${ }^{4}$. Furthermore, we consider different fuel standards (FUELS) that lead to emission reductions for an unchanged engine and inspection and maintenance schemes (IM). These inpection and maintenance schedules can take the form of remote road sensing or the installation of on board diagnostics. Also non-technical control measures are included. More specifically, we look at public transport subsidies (PUB) of up to $40 \%$ reductions in fares, scrappage schemes (SCR) and structured circulation taxes (SM) that relate the circulation tax to the average yearly emission of certain pollutants for that type of car.. The sets in the two categories of Technical Standards (TED and TEG) only contain global control measures and are indicated in bold in the table. All control measures in the other categories are assumed to be local. Measures in the non technical category contain measures for the emissions of power plants and other large combustion installations.

\begin{tabular}{|c|c|c|c|c|c|c|c|}
\hline \multicolumn{7}{|c|}{ Transport } & \multirow{3}{*}{$\begin{array}{c}\text { Non } \\
\text { Transp }\end{array}$} \\
\hline \multicolumn{2}{|c|}{$\begin{array}{l}\text { Technical } \\
\text { Standards }\end{array}$} & \multirow[t]{2}{*}{$F U E L S$} & \multirow[t]{2}{*}{$I M$} & \multicolumn{3}{|c|}{ Non Technical } & \\
\hline$T E D$ & $T E G$ & & & $P U B$ & $S M$ & SCR & \\
\hline TED00 & TEG00 & F00 & IM00 & PUB00 & SM00 & SCR00 & NT00 \\
\hline TED01 & TEG01 & F04 & IM01 & PUB01 & SM03 & SCR01 & NT01 \\
\hline TED03 & TEG03 & F05 & IM02 & PUB02 & SM05 & SCR02 & NT02 \\
\hline TED04 & TEG04 & F06 & & & & & NT04 \\
\hline TED06 & TEG06 & F08 & & & & & NT06 \\
\hline TED07 & TEG07 & F09 & & & & & NT08 \\
\hline TED08 & TEG08 & F10 & & & & & NT10 \\
\hline TED09 & TEG10 & F14 & & & & & \\
\hline TED10 & TEG11 & & & & & & \\
\hline TED12 & TEG12 & & & & & & \\
\hline TED13 & TEG14 & & & & & & \\
\hline TED14 & TEG15 & & & & & & \\
\hline TED16 & & & & & & & \\
\hline TED17 & & & & & & & \\
\hline
\end{tabular}

Table 1: Categories and sets of control measures

\subsection{Results}

In table (A1) in the appendix, the results for different optimization runs of the model can be found. From the third column onwards, each column gives the results of a different run. Within each column, we first present a general overview of the results of

\footnotetext{
4 These technical standards are engineering packages that achieve increasing percentages of emission reduction for cars and light duty vehicles and this for the different pollutants considered.
} 
that scenario. Here, one can find the gross costs, this is the total EU-wide cost of introducing the control measures net of benefits or fines. Also the total benefits and fines and the total net costs, defined as the gross cost minus the benefits are given. In the lower columns we report results for each of the 7 regions: the costs, the composition of the bundle chosen, and the environmental effectiveness of that bundle are specified.

The first scenario in the table is called the base case because we will compare all other scenarios with this one. In the base case, we follow the standard AOP2 methodology, the benefits for overachievement are equal to zero for each pollutant, while the fines for underachievement are infinity in all cases. From table (A1) follows that the EU-wide costs for implementing the control measures necessary for attaining the required targets in the different regions are equal to 4629.143 million Euro. In the remainder of the column, further details about the specific choice for each region can be found. The results should be interpreted as follows. For the region of Athens, the gross cost of the bundle introduced in that region is 251.19 million Euro. In the next part, the composition of the bundle selected is given. We can see that from the category FUELS, the set F04 is chosen and this set has a cost of 15.2 Million Euro. The set IM03 was picked from IM which has a cost of 7.26 million Euro and so on. In the third part, the achieved effectiveness for each pollutant is shown. Remark that for Ozone, this is not only the effectiveness of the bundle selected by this region, but also the sum of the effect that other regions have on the level of Ozone in this region. We can see that in Athens a reduction of $60.72 \%$ was achieved for Ozone (to be compared with the required $45 \%$ ) , 35.12\% for Regional NOx and so on. The results for the other six regions should be interpreted in the same way as just explained. If we compare the achieved effectiveness in the different regions with the required targets for each region which are presented in the second column, we can detect the constraints that are binding. These are the Ozone-constraint in Den Haag and the constraints for Urban NOx in Athens, Madrid and Milano. Later on in the discussion, it will be quite often these urban air quality constraints that drive the results obtained.

A first extension of the base case is to allocate benefits when a region overachieves its required targets. We consider three cases: a benefit of first 20 Euro and then 30 Euro per percent per capita overachievement of the target for Urban NOx and a benefit of 5 Euro per percent per capita overachievement of the targets for Urban NOx and Ozone. The results can be found in table (A1) in the columns "Ben NOx Urb 20", "Ben NOx Urb 30" and "Ben NOx Urb Ozone 5" respectively. It is trivial that the net total costs are smaller compared with the base case. Remark however that the gross costs are higher in the three cases. This is an indication that stronger control measures have been chosen (a more expensive control measure has also a greater effect). Secondly, in most cases, the amount of overachievement of a target increases for the pollutant(s) with a benefit, while for the pollutants without a benefit the picture is mixed. Although it holds for most control measures that if they have more effect on one pollutant, they also are more effective for the other ones, the selection of control measures is apparently more aimed at the pollutants with a benefit. Thirdly, also the composition of the bundles changes, as well for the part of local control measures as for the part of global control measures. When we increase the benefit for Urban NOx from 20 to 30 Euro, it is mainly the choice of the global control measures that changes, the local control measures selected remain more or less the same. Finally, 
remark that even a relative small benefit of 5 Euro has a quite large impact on the bundles selected, this shows the importance of incorporating benefits for overachievement in the analysis.

In contrast with the case of benefits, one can include fines for underachievement in the analysis, hereby allowing a region not to satisfy completely all targets for the different pollutants. In the columns "Fines NOx Urb Ozone 50" and "Fines NOx Urb Ozone 100" of table (A1) we introduced a fine of 50 and 100 Euro respectively per percent underachievement per capita of the target for Urban NOx and Ozone. A first important point is that the net costs are both smaller than in the base case. In case of a fine of 50 Euro, we find lower gross costs but a higher fine than when the fine is 100 . This is intuitive since a lower fine gives a higher incentive for a region not to introduce a (relatively) expensive control measure to reach a target, but to pay the (relatively lower) fine instead. Furthermore, the overachievement decreases in almost all cases. Also the composition of the bundles that are chosen by the regions change. When a fine of 50 Euro is imposed, less strong global control measures are selected than in the base case. Furthermore, we find an underachievement of a target in three cases: Ozone in Den Haag and Urban NOx in Madrid and Milano. Recall that these were also cases in which the constraint for the specific pollutant and region was binding in the base case. With a fine of 100 Euro, only an underachievement is found for Ozone in Den Haag, all other targets are satisfied. However, the cost (4286.927 million Euro) is quite a bit lower than in the base case (4629.143 million Euro). The conclusion is that when we allow for the possibility of underachievement of targets by means of fines, we can achieve a cheaper solution. The reason for this is that when a region has huge difficulties in reaching its targets, it might have to introduce strong control measures and hence also strong global control measures. The other regions then have to implement these global control measures as well. This means that the EU-cost is increased. When we allow a region to undersatisfy (slightly) a target, it might be possible that the overall solution changes only marginally in terms of achieved effectiveness, but is less expensive. Of course, an important parameter is the level of the fine. A fine of 200 Euro for Urban NOx and Ozone e.g. results again in the same solution as in the base case. It is clear that also other types of fines, for instance non-linear schemes could be examined as well.

In the last column we tackle the problem of the decentralization of local measures. As has been explained before, we mimic the problem by imposing that a minimum of the reduction efforts has to be realized via global control measures. In this way, we get an idea of the consequences of this problem. When we set this minimum effort at $10 \%$, total costs increase significantly and of course more global control measures are introduced into the optimal bundle.

\section{Conclusion}

In this paper we examined the cost-efficiency methodology to decide on new emission standards for cars and fuel quality standards in Europe. We detected two important problems that could lead to a bias against European wide measures: the overachievement problem and the problem of decentralization of local measures. We showed how the first problem can be solved by attributing benefits to 
overachievement and the second problem can be handled by using explicitly the behaviour of the local government as constraint in the problem.

We demonstrated numerically that both problems are important in the Auto-oil set up and that a correct solution of the two problems can lead to important welfare gains.

There are many caveats in this analysis. One interesting extension is the transformation of the constraint on global measures into a weaker constraint where the weakening implies giving up part of the economies of scale of the global measure.

\section{Bibliography}

Bickel, P., S. Schmid, W. Krewitt and R. Friedrich (eds) (1997), External Costs of Transport in ExternE, Final Report, Stuttgart: IER.

Degraeve Z., Koopman, G.J., (1998), Achieving air quality standards in the European Union, Operations Research, Vol. 46, № 5, Sept - Oct, p 643-654.

Degraeve, Z., Koopman, G., Denis, C., Teunen, L., (1998), Deriving and Selecting Policy Instruments to Meet Air Quality Standards in the European Union, in : Proost, S., Braden, J., Climate Change, Transport and Environmental Policy - Empirical Applications in a Federal System, Edward Elgar.

DRI-KULeuven, (1999), the TREMOVE model, Auto-oil programme, Commission of the Eruopean Communities,

European Commission, 1996, "Air Quality Studies for the Auto/Oil Programme," Report of Subgroup 2, DG XI, Brussels, Belgium.

Hall J;, A.M.Winer, M.Kleinman,F.Lurman,S.Dcolome,V.Brajer (1992), "Valuing the benefits of clean air", Science, 255, 812-17

IVM, NILU, IIASA, (1997), Economic Valuation of air quality targets for sulphut dioxide, nitrogen dioxide, fine particulate matter and lead, Final report, European Commission, DGXI.

Krupnick A., Portney P.R. (1991), Controlling Urban Air Pollution : a Benefit-Cost Assessment, Science, 252, 522-528.

Oates, W.E., Portney P.R., McGartland A.M., (1989), The net benefits of incentive based regulation: a case study of environmental standard setting, American Economic Review , 79 (5), p 431-53.

Roberts M.J., Spence M., (1976), Effluent charges and licenses under uncertainty, Journal of Public Economics, Vol. 5.

Simpson, D., 1991, Update 1995, "Long Period Modeling of Photochemical Oxidants in Europe," EMEP, Cooperative Programme for Monitoring and Evaluation of the Long Range Transmission of Air Pollutants in Europe, Swedish Environmental Research Institute, EMEP MSC-W Report 2/91. 


\section{Appendix 1: Formal description of the LEUVEN II model}

\subsection{Definitions}

In this section, we present key definitions and discuss the conceptual modeling framework. We define a control measure to be an instrument capable of reducing emissions. Instruments can be combined to form sets of control measures. We classify sets of control measures in a table such as table 1 . So as a result, we consider 8 categories of control measures. For each of those, a finite list of sets of control measures was developed. An example of such lists can be found in table 1. Each set of control measures is characterized by its cost and its effectiveness, i.e. its emission reduction potential, expressed in terms of the percentage reduction in economy-wide emissions forecast in 2010 if no additional policy action were taken. The use of the discrete sets of control measures is not restrictive for our modeling purposes: the same instrument such as a reduction in public transport fares but applied at a different intensity, e.g. a $10 \%$ or a $40 \%$ reduction, is considered to be a different type of measure.

A control measure is also classified according to its geographical scope. Global control measures must be introduced simultaneously throughout the European Union. They are indicated in bold in table 1. So in our analysis they are restricted to the technical control measures. Of course, other categories can contain global control measures as well. We assume that control measures from the remaining categories are local. Local measures can be tailored to a specific regional situation and can hence be introduced at various intensities throughout the EU.

We specify the sets and parameters presented above by the following notation:

$\mathrm{R} \quad$ : set of regions, index $\mathrm{j}$,

$\mathrm{P} \quad$ : set of pollutants, index $\mathrm{p}$,

$\mathrm{P}_{\text {local }}$ : set of local pollutants, index 1 ,

M : set of all control measures,

C : set of categories of control measures,

$C_{t} \quad$ : set of control measures of category $t, t=1,2, \ldots,|C|$, index $i_{t}$,

$v_{i_{t} j}^{t} \quad$ : cost of introducing set of control measures $i_{t}$ in region $j, t=1,2, \ldots,|C|$,

$\forall \mathrm{i}_{\mathrm{t}} \in \mathrm{C}_{\mathrm{t}}, \forall \mathrm{j} \in \mathrm{R}$,

$e_{i_{t} j 1}^{t} \quad$ : effectiveness of set of control measures $i_{t}$ for the abatement of pollutant 1 in

region $\mathrm{j}, \mathrm{t}=1,2, \ldots,|\mathrm{C}|, \forall \mathrm{i}_{\mathrm{t}} \in \mathrm{C}_{\mathrm{t}}, \forall \mathrm{j} \in \mathrm{R}, \forall 1 \in \mathrm{P}_{\text {local }}$. 
$\mathrm{d}_{\mathrm{pj}} \quad$ : required abatement of pollutant 1 in region $\mathrm{j}$ as a percentage of emissions level in 2010, $\forall \mathrm{p} \in \mathrm{P}, \forall \mathrm{j} \in \mathrm{C}$,

The problem for each region consists of selecting sets of control measures from the 8 categories $C_{t}, t=1,2, \ldots,|C|$, taking exactly one set from each category, to form a bundle that would achieve the required emissions reduction at least cost. In table 1, the empty set is also included as the first element (being x00) in each category allowing for the possibility not to choose a set of control measures from the corresponding category. We then introduce the following notation:

B : set of bundles, index $b$,

$\mathrm{B}_{\mathrm{i}_{\mathrm{t}}}^{\mathrm{t}} \quad$ : subset of bundles containing set of control measures $\mathrm{i}_{\mathrm{t}}, \mathrm{t}=1,2, \forall \mathrm{i}_{\mathrm{t}} \in \mathrm{C}_{\mathrm{t}}$.

$\mathrm{z}_{\mathrm{bj}}=1$, if bundle $\mathrm{b}$ will be introduced in region $\mathrm{j}$, 0 , otherwise, $\forall \mathrm{b} \in \mathrm{B}$, $\forall \mathrm{j} \in \mathrm{R}$,

$\mathrm{f}_{\mathrm{bj}} \quad$ : cost of bundle $\mathrm{b}$ in region $\mathrm{j}, \forall \mathrm{b} \in \mathrm{B}, \forall \mathrm{j} \in \mathrm{R}$,

ne $_{\mathrm{bjl}}$ : net effectiveness of bundle $\mathrm{b}$ for the abatement of pollutant 1 in region $\mathrm{j}$, $\forall \mathrm{b} \in \mathrm{B}, \forall \mathrm{j} \in \mathrm{R}, \forall 1 \in \mathrm{P}_{\text {local }}$,

The cost of the bundle is simply the sum of the cost of the sets of control measures selected. Since the interaction effects with respect to costs are negligible, this additive functional form is acceptable:

$$
f_{b j}=\sum_{t=1}^{|C|} v_{i_{t} j}^{t} \quad \forall b \in B, \forall j \in R
$$

The effectiveness of the bundle cannot likewise be computed as there potentially exist interaction effects among some of the categories. This requires the effectiveness of bundles to be partly endogenous. In some cases there are synergy effects implying that the simultaneous introduction of two sets of control measures leads to an abatement of emissions that is larger than the sum of the emissions reduction potential of the individual sets. This will be the case when sets of control measures are complementary. However, generally, the joint impact will be lower than the sum of the two emissions reduction. Nevertheless, we have to properly take the cumulative effectiveness of combining several sets of control measures into account. This is because a second set of control measures can only be applied to the emissions level remaining after the first set has had its effect. The effectiveness of a bundle is computed as follows :

$$
e_{\left(i_{1} \ldots i_{7}\right) j l}=100\left(1-\left(1-e_{i_{1}, j l}^{1}-e_{i_{2}, j l}^{2}\right) \prod_{t=3}^{7}\left(1-e_{i_{t} j l}^{t}\right)\right)
$$


Its net effectiveness then amounts to :

$$
n e_{b j l}=e_{\left(i_{1} \ldots i_{7}\right)_{j l}}+e_{i_{9} j l}^{8} \quad \forall b \in B, \forall j \in R, \forall l \in P_{\text {local }}
$$

\subsection{The treatment of ozone}

Ozone can be treated in different ways. The most ideal way would be to have exact relationships between ozone and its precursors. If these are not available, an approximation could be applied by using blame matrices, as was done in the LEUVEN I model. A final possibility is to translate the targets for ozone into targets for its precursors. In the remainder of the text, we explain the second approach. The third approach is similar, only the constraints concerning ozone disappear and constraints for the precursors, analogous to the ones for the other local pollutants, are added.

So, the approach taken in the LEUVEN II model is to use blame matrices, one for each precursor of ozone (typically these are regional NOx regional VOC). The coefficients of these matrices give the percentage reduction in ozone levels in a particular region due to a $1 \%$ reduction in emissions of the corresponding precursor in another region. The elements are denoted in the following way:

$\mathrm{a}_{\mathrm{kjl}} \quad$ : entries of the blame matrix, impact of reducing the ozone precursor 1 in region $\mathrm{k}$ on the reduction of ozone in region $\mathrm{j}, \forall \mathrm{k}, \mathrm{j} \in \mathrm{R}, \mathrm{l}=\mathrm{VOC}$, NOx.

The effect of a bundle $b$ on ozone in region $\mathrm{j}$ is then equal to:

$$
\sum_{l=V O C, N O x} \sum_{k=1}^{|R|} a_{k j l}\left(n e_{b k l} z_{b k}\right)
$$

So, we take the net effectiveness of a bundle $\mathrm{b}$ on the precursors for ozone (regional NOx and VOC) in region $\mathrm{k}$, we account for the effect of region $\mathrm{k}$ on region $\mathrm{j}$ by multiplying with the appropriate element in the blame matrix and we sum over all regions $\mathrm{k}$ to get the effect on region $\mathrm{j}$.

\subsection{Benefits or fines for deviating from the emission ceilings}

In the model as it would be formulated at the moment, the constraints on the achievement of the required targets will be satisfied as tightly as possible. The reason for this is that a region has no incentive to do better than the target since overachieving certain targets only results in a higher cost. The exception on this is ozone, because the model takes account interactions between a certain region and the other regions. In order to provide an incentive for the different regions to oversatisfy some targets, we will attach a 'reward' to an overachievement. This reward can have a number of causes, since an overachievement implies a cleaner environment, which in turn can lead to smaller medical expenditures, less damage from pollution and so on. In addition to the benefits of a cleaner environment, there is another, conceptual reason to include rewards for overachievement in the analysis. In an extended exercise 
like the Auto-Oil II Programme, in which a number of pollutants and regions are included, there will be often an overachievement of the targets for certain pollutants in certain regions. This might imply a bias against the use of uniform, global control measures. The main idea is that global control measures, such as European wide standards, tend to generate an overachievement due to their lack of flexibility.

On the other hand, it is also possible that a region or a country cannot satisfy its targets for one or more local pollutants (recall that for ozone a region or country can be helped out by another region). If one solves the model, this will of course result in an infeasible solution. By introducing fines if a region or country does not satisfy its targets, we can overcome this problem. Introducing fines means that a region or country will balance the fine that has to be paid versus the cost of the control measures that are necessary to achieve the target. This means that when fines are low, a region or country might choose not to reach its targets although it in principle could, because the fines for underachievement are lower than the costs for reaching the targets. This shows that the importance of setting the level of the fine. In the next section we will introduce benefits and fines in the formal model.

Now that we have argued why it is interesting to take into account benefits of overachievement and fines for underachievement of targets, we will now discuss more formally what are the consequences for the LEUVEN II-model. In a first step, we need to determine by how much a target is over- or undersatisfied. This is done by using socalled slack variables. We define a slack variable as the absolute value of the difference between the target and the effectiveness achieved. Hence, it is clear that we need slack variables for the constraints on the required emission abatements for the regions as well as for the required national emission abatement. We will denote them in the following way.

$\mathrm{sro}_{\mathrm{pj}}$ : slack variable for overachievement of regional requirement, $\forall \mathrm{p} \in \mathrm{P}$,

$$
\forall \mathrm{j} \in \mathrm{R},
$$

$\mathrm{sru}_{\mathrm{pj}}$ : slack variable for underachievement of regional requirement, $\forall \mathrm{p} \in \mathrm{P}$,

$$
\forall \mathrm{j} \in \mathrm{R},
$$

Let us finally introduce the notation for the benefits and fines:

$$
\begin{aligned}
& \mathrm{br}_{\mathrm{pj}} \quad \text { : benefit of overachievement of a regional target, } \forall \mathrm{p} \in \mathrm{P}, \forall \mathrm{j} \in \mathrm{R}, \\
& \mathrm{fr}_{\mathrm{pj}} \quad \text { : fine of underachievement of a regional target, } \forall \mathrm{p} \in \mathrm{P}, \forall \mathrm{j} \in \mathrm{R} \text {, }
\end{aligned}
$$

\subsection{The implementation problem of local measures}

The LEUVEN II-model determines the mix of local and global control measures that is most cost-effective from a European-wide point of view. In doing so, we assume that the local authorities implement the measures that are chosen. However, a bundle 
that is the most cost-effective from a European-wide perspective, is not necessarily so for a region. This means that local authorities might have incentives to select other local measures than the ones in the 'optimal' bundle. Intuitively, we can expect that the local government will not implement sufficient local control measures because it does not have the incentives to do so. Therefore, the optimal mix selected in the Auto Oil Programme is only optimal in as far as the European policy maker can indeed correct the local government behavior. If this is not so, one will tend to favor again more the European wide, global control measures.

The same arguments could of course be made on the national level, since also countries might have incentives not to implement the optimal bundle from a European point of view. However, we will only discuss the case of local authorities (this means at the level of the regions), the case for countries is very similar to this case.

In the discussion above, it was argued that a consequence of the implementation problem of local control measures is that this has an influence on the mix between global and local control measures. Hence, we will use this result to introduce the implementation problem formally into the LEUVEN II-model. More specifically, we add a constraint that states that a certain percentage of a target needs to be achieved by global control measures. More formally, let us introduce the following notation:

gne $_{\mathrm{bjl}}$ : net effectiveness of bundle $b$, achieved by the global control measures in bundle $\mathrm{b}$, for the abatement of pollutant 1 in region $\mathrm{j}, \forall \mathrm{b} \in \mathrm{B}, \forall \mathrm{j} \in \mathrm{R}, \forall \mathrm{l}$

$$
\in \mathrm{P}_{\text {local }}
$$

$\mathrm{g}_{\mathrm{lj}} \quad$ : percentage of the required abatement of pollutant 1 in region $\mathrm{j}$ to be achieved by global control measures, $\forall 1 \in \mathrm{P}_{\text {local }}, \forall \mathrm{j} \in \mathrm{C}$,

\subsection{The formal model}

The formal model can be formulated as follows:

i) Minimize total cost of introducing bundles ;

$\operatorname{Min} \quad \sum_{j=1}^{|R|} \sum_{b=1}^{|B|} f_{b j} z_{b j}-\sum_{l \in P_{l}} \sum_{j=1}^{|R|} b r_{l j} s r o_{l j}-\sum_{j=1}^{|R|} b r_{O 3 j} s r o_{O 3_{j}}+\sum_{l \in P_{l}} \sum_{j=1}^{|R|} f r_{l j} s r u_{l j}+\sum_{j=1}^{|R|} f r_{O 3 j} s r u_{O 3 j}$

Subject to

(ii) Achieve the required regional emissions abatement ;

$$
\sum_{b=1}^{|B|} n e_{b j l} z_{b j}-\operatorname{sro}_{l j}+s r u_{l j}=d_{l j} \quad \forall l \in P_{l o c a l}, \forall j \in R
$$


(iii) Achieve the required ozone abatement ;

$\sum_{l=V O C, N O x} \sum_{k=1}^{|R|} a_{k j l}\left(\sum_{b=1}^{|B|} n e_{b k l} z_{b k}\right)-s r o_{O 3 j}+s r u_{O 3 j}=d_{O 3 j} \quad \forall j \in R$

(iv) Choose one bundle for each region ;

$\sum_{b=1}^{|B|} z_{b j}=1 \quad \forall j \in R$

(v) Global control measures have to be introduced throughout the EU ;

$\sum_{b=1}^{\left|B_{i_{t}}^{t}\right|} z_{b j}=\sum_{b=1}^{\left|B_{i_{t}}^{t}\right|} z_{b j+1} \quad t=1,2, \forall i_{t} \in C_{t}, j=1, \ldots,|R|-1$

(vi) Achieve the required share of global control measures ;

$$
\begin{array}{lc}
\sum_{b=1}^{|B|} g n e_{b j l} z_{b j} \geq g_{l j} d_{l j} & \forall l \in P_{l o c a l}, \forall j \in R \\
\sum_{l=\text { VOC }, N O X} \sum_{k=1}^{|R|} a_{k j l}\left(\sum_{b=1}^{|B|} g n e_{b k l} z_{b k}\right) \geq g_{O 3 j} d_{O 3 j} & \forall j \in R
\end{array}
$$

(viii) Define the variables $0 / 1$;

$$
z_{b j} \in\{0,1\} \quad \forall b \in B, \forall j \in R
$$

A difficulty with this formulation is that for realistic problem dimensions, the number of variables $\mathrm{Z}_{\mathrm{bj}}$ that needs to be included in the model will be extremely large (this is $|\mathrm{R}|^{*}|\mathrm{~B}|$, and $|\mathrm{B}|$ increases exponentially). For the column generation approach that was used to tackle this difficulty, we refer to Degraeve and Koopman (1998).

\section{Appendix 2: Results}

Table A2 contains the results of the different runs of the model. We refer to the main text of this paper for a discussion of the results. 


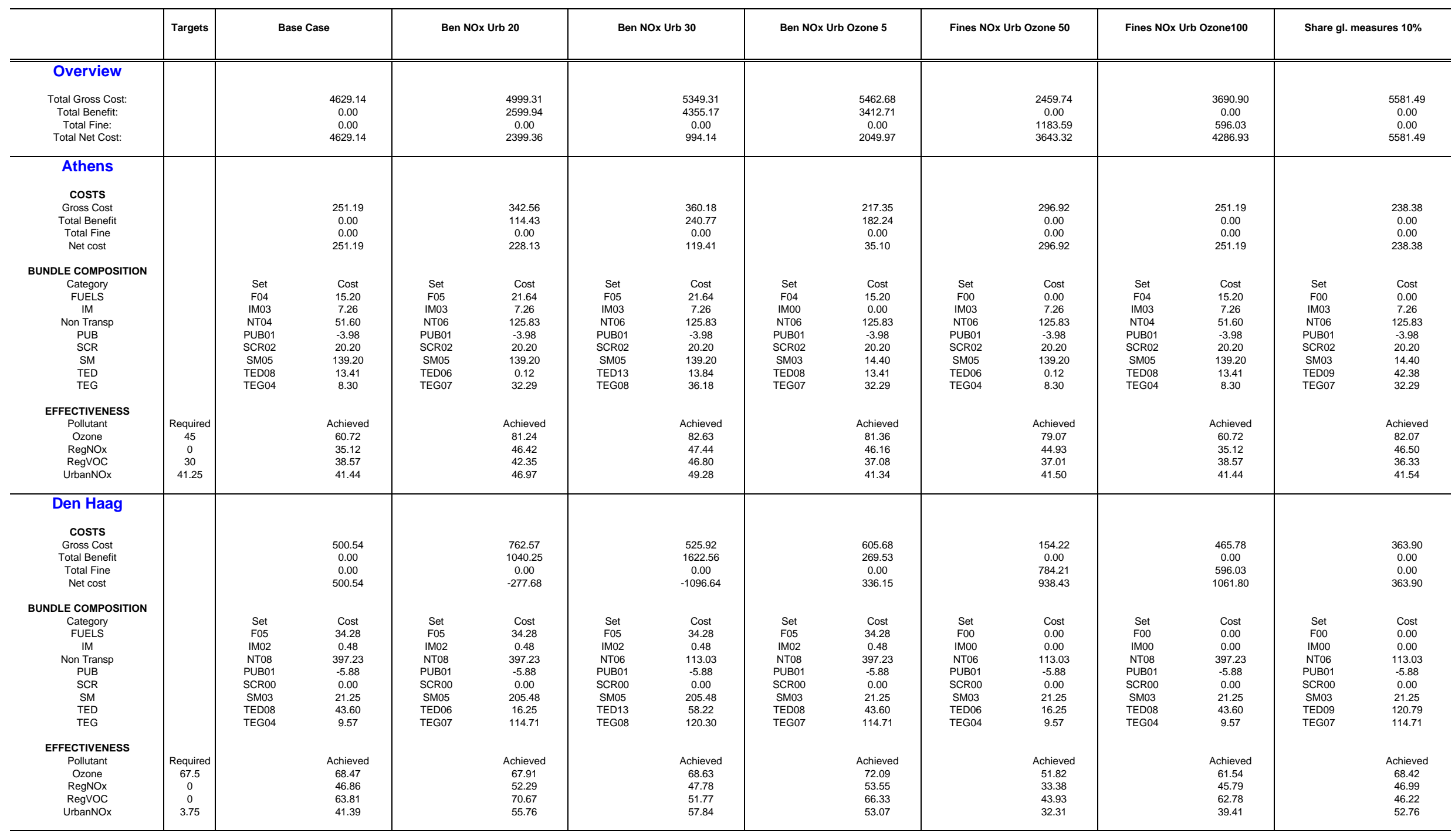




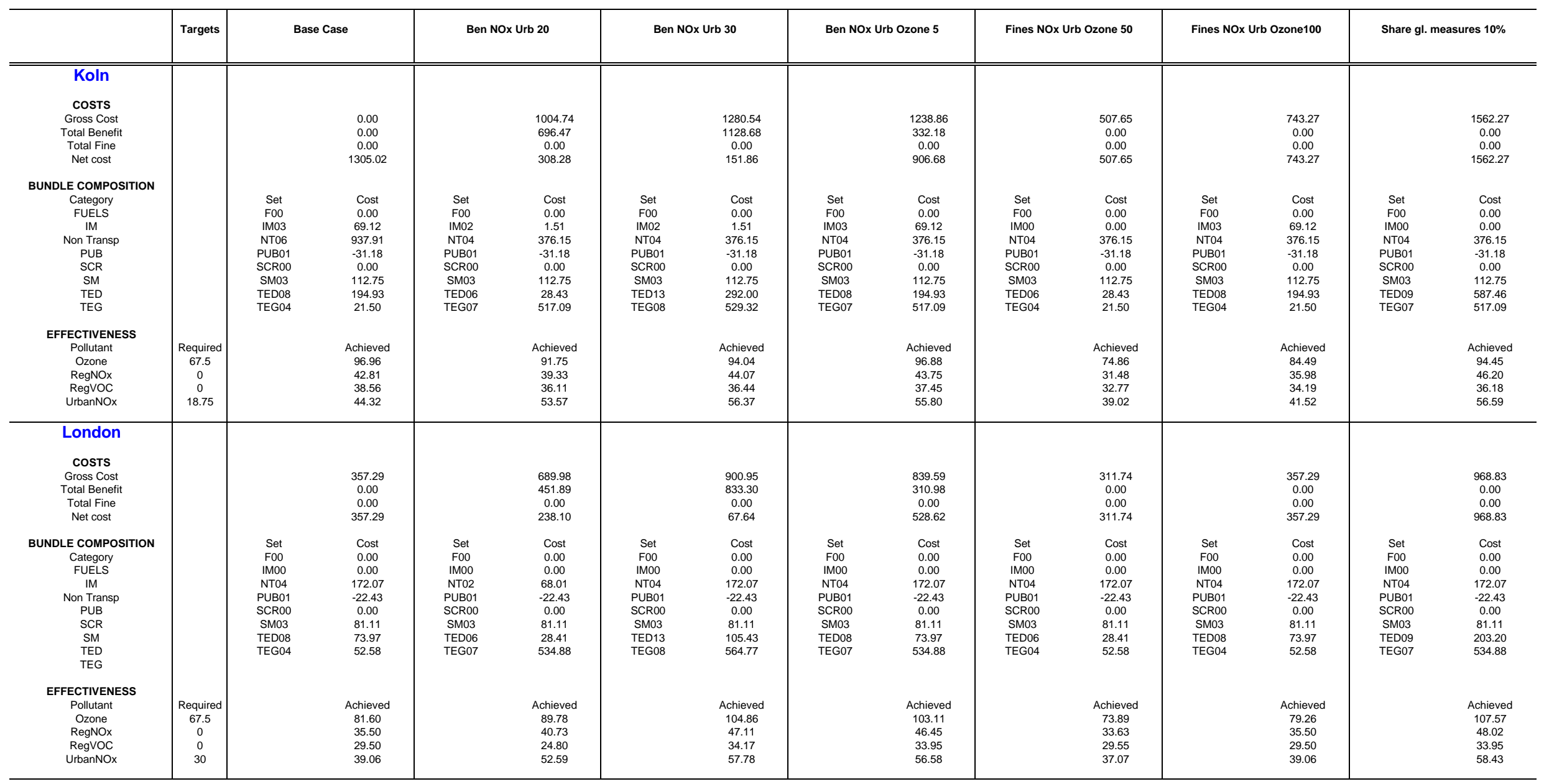




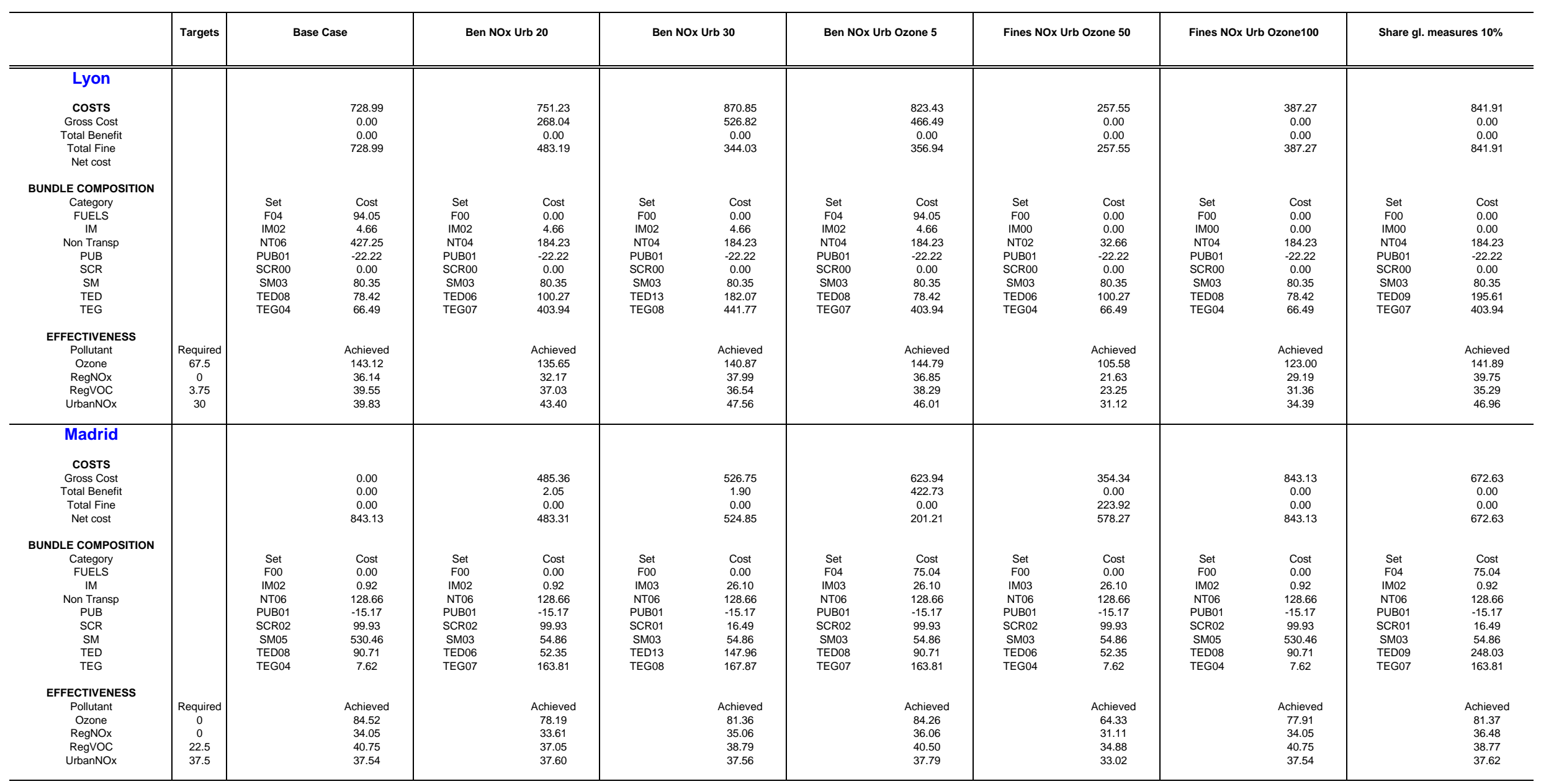




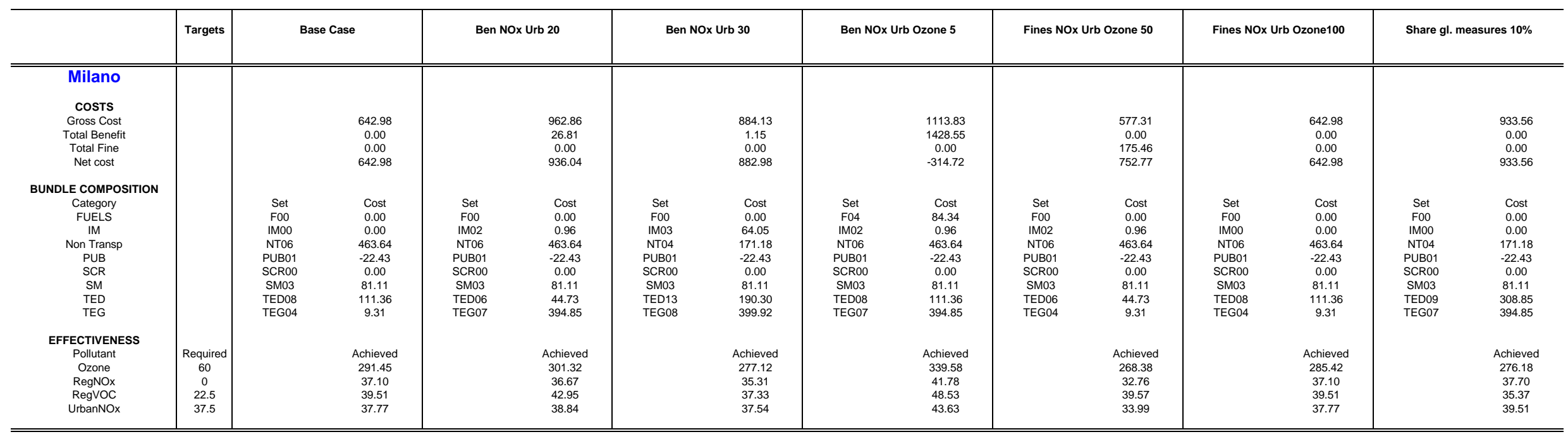


The Center for Economic Studies (CES) is the research division of the Department of Economics of the Katholieke Universiteit Leuven. The CES research department employs some 100 people. The division Energy, Transport \& Environment (ETE) currently consists of about 15 full time researchers. The general aim of ETE is to apply state of the art economic theory to current policy issues at the Flemish, Belgian and European level. An important asset of ETE is its extensive portfolio of numerical partial and general equilibrium models for the assessment of transport, energy and environmental policies.

\section{WORKING PAPER SERIES}

$n^{\circ} 2001-25$

$n^{\circ} 2001-24$

$n^{\circ} 2001-23$

$n^{\circ} 2001-22$

$n^{\circ} 2001-21$

$n^{\circ}$ 2001-20

$n^{\circ} 2001-19$

$n^{\circ} 2001-18$

$n^{\circ} 2001-17$

$n^{\circ}$ 2001-16

$n^{\circ} 2001-15$

$n^{\circ} 2001-14$

$n^{\circ}$ 2001-13

$n^{\circ} 2001-12$

$n^{\circ} 2001-11$

$n^{\circ}$ 2001-10

$n^{\circ} 2001-09$
Degraeve, Z., Proost, S. and Wuyts, G. (2001), Cost-efficiency methodology for the selection of new car emission standards in Europe

Bigano, A. (2001), Environmental Dumping, Transboundary Pollution And Asymmetric Information - Some Insights For The Environmental Regulation Of The European Electricity Market

Mayeres, I., and Proost, S. (2001), Can we use transport accounts for pricing policy and distributional analysis?

Moons, E., Loomis, J., Proost, S., Eggermont, K. and Hermy, M. (2001), Travel cost and time measurement in travel cost models

Calthrop, E. (2001), Pricing a stock-constrained congestible facility

S. Proost, K. Van Dender, C. Courcelle, B. De Borger, J. Peirson, D. Sharp, R. Vickerman, E. Gibbons, M. O'Mahony, Q. Heaney, J. Van den Bergh, E. Verhoef (2001), How large is the gap between present and efficient transport prices in Europe?

Van Dender, K., and Proost, S. (2001), Optimal urban transport pricing with congestion and economies of density

Eyckmans, J., Van Regemorter, D., and van Steenberghe, V. (2001), Is Kyoto fatally flawed? An analysis with MacGEM

Van Dender, K. (2001), Transport taxes with multiple trip purposes

Proost, S., and Van Regemorter, D. (2001), Interaction between Local Air Pollution and Global Warming Policy and its Policy Implications

Franckx, L. (2001), Environmental enforcement with endogenous ambient monitoring

Mayeres, I. (2001), Equity and transport policy reform

Calthrop, E. (2001), On subsidising auto-commuting

Franckx, L. (2001), Ambient environmental inspections in repeated enforcement games

Pan, H. (2001), The economics of Kyoto flexible mechanisms: a survey

Calthrop, E. (2001), When consumers can decide not to pay a tax: enforicing and pricing urban on-street parking space

Franckx, L. (2001), Ambient environmental inspections eliminate the need for marginal deterrence 